\title{
O LÚDICO PARA A ÁREA DA SAÚDE: PERSPECTIVAS POR MEIO DO DISCURSO DO SUJEITO COLETIVO (DSC)
}

\author{
THE LUDIC FOR THE HEALTH AREA: PERSPECTIVES THROUGH THE SPEECH OF \\ THE COLLECTIVE SUBJECT (DSC)
}

Maria Bethânia Tomaschewski Bueno ${ }^{1}$, Fernando Augusto Treptow Brod ${ }^{2}$

Recebido: agosto/2018 Aprovado: agosto/2021

\begin{abstract}
Resumo: O objetivo do estudo foi analisar as perspectivas de sujeitos sobre o ensino do lúdico na saúde. A metodologia utilizada foi a de abordagem qualitativa, com aplicação de um questionário com perguntas abertas a oito sujeitos de áreas diversas, não somente da área da saúde. 0 questionário foi aplicado durante os meses de julho a agosto de 2017 e os depoimentos foram tratados pela técnica do Discurso do Sujeito Coletivo (DSC), segundo Lefèvre e Lefèvre (2005). 0 questionamento originou três discursos coletivos denominados de 'Atividade prazerosa para o desenvolvimento da criatividade', 'O Lúdico auxilia de maneira positiva no processo de aprendizagem' e 'O Lúdico na saúde facilita a interação, a criatividade e o desenvolvimento'. Os depoimentos ressaltaram a relevância da abordagem do lúdico no ensino na área da saúde, promovendo estímulos nas interações dos envolvidos e proporcionando atividades criativas, prazerosas e afetivas.
\end{abstract}

Palavras-chave: Lúdico; Ensino em Saúde; Educação.

Abstract: The objective of the study was to analyze the perspectives of subjects about the teaching of ludic in health. The methodology used was a qualitative approach, with application of a questionnaire with open questions to eight subjects from different areas, not only from the health area. The questionnaire was applied during the months from July to August 2017 and the statements were treated by the Discourse of the Collective Subject (DSC) technique, according to Lefèvre and Lefèvre (2005). The questioning originated three collective discourses named 'Pleasurable activity for the development of creativity', 'The ludic helps in a positive way in the learning process' and 'The ludic in health facilitates interaction, creativity and development'. The statements highlighted the relevance of the ludic approach in teaching in the health area, promoting stimuli in the interactions of those involved and providing creative, pleasurable, and affective activities.

Keywords: Ludic; Health Education; Education.

\section{Introdução}

Os profissionais da área da saúde possuem contato direto com os indivíduos por meio do acolhimento, na escuta dos relatos dos pacientes e também do brincar que, esses profissionais compreendem e planejam em conjunto com seus conhecimentos e técnicas o tratamento adequado e singular ao seu paciente. Esse conjunto de fatores envolve a humanização do

http://orcid.org/0000-0002-6394-9702 - Mestranda em Ciências e Tecnologias na Educação pelo Instituto Federal de Educação, Ciência e Tecnologia Sul-rio-grandense Campus Pelotas - Visconde da Graça (IFSul-CaVG), Pelotas, Rio Grande do Sul, Brasil. Rua Santiago Dantas, 235, Casa: 231, Bairro: Três Vendas, CEP: 96065-450, Pelotas, Rio Grande do Sul, Brasil. E-mail: bethaniatomaschewsky@gmail.com

2 (D) http://orcid.org/0000-0002-5754-2869 - Doutor em Educação em Ciências pela Universidade Federal do Rio Grande (FURG). Docente no Instituto Federal de Educação, Ciência e Tecnologia Sul-rio-grandense Campus Pelotas - Visconde da Graça (IFSul-CaVG), Pelotas, Rio Grande do Sul, Brasil. Avenida Ildefonso Simões Lopes, 2791, Bairro: Três Vendas, CEP: 96060-290, Pelotas, Rio Grande do Sul, Brasil. E-mail: ftbrod@gmail.com 
atendimento e, dentro dessa conjuntura, o brincar possui uma relação intencional na prática em saúde.

Maturana (2004) reflete sobre a importância do brincar e das interações entre os seres e como o modelo que se constitui nos dias atuais possui em suas características a competição, tem desenvolvido um desencontro de interações que não possibilita aos indivíduos cooperarem entre si, pois o que define é competir e produzir cada vez mais. Assim, por consequência, não há ênfase para os conteúdos delineados a brincadeiras e emoções.

Segundo Maturana (2004), o brincar está ligado a uma atividade primorosa, com consequências além da interação, como autoconsciência e consciência do ambiente. Mas esse fator somente acontece de maneira positiva quando de fato a interação ocorre em sua totalidade, isto é, quando a atividade do brincar é realizada e desfrutada pelos indivíduos com imersão emocional e racional.

Nesse sentido, a abordagem desta pesquisa remete ao lúdico e ao ensino das atividades dele. Para Massa (2015), o lúdico tem uma rede de significados como o brincar, o jogar, o brinquedo, o lazer, a recreação, as representações, a imaginação, dentre outros. Em um modelo que possui como sentido a competitividade e com a persistência de interações em que os indivíduos são oponentes, o ensino do lúdico é, diante dessas características, algo controverso e irrelevante.

O estudo de Cintra, Proença e Jesuino (2010) foi fundamentado em Vigotsky para abordar o ensino do lúdico e a importância dele para a aprendizagem da criança. Os autores frente a teoria, em que os seres interagem e são influenciados pelo ambiente, consideraram que um dos benefícios da ludicidade na educação é o de aprender com significância, o que desenvolve o físico, o cognitivo, o psicológico, dentre outros.

Sob o mesmo ponto de vista, na educação superior e especificadamente na área da saúde, o lúdico para o desenvolvimento proposital possibilita a sociabilização, a comunicação assertiva e a abordagem de determinados temas de diferentes maneiras (BUENO; BROD; CORRÊA, 2018; BOLORINO et al., 2020; MIRANDA; SOARES-SOBRINHO; CASTRO, 2019; RIBEIRO; BONINI; MELO, 2020; PEREIRA et al., 2021). Seja a interação aluno-aluno, professor-aluno ou profissionalpaciente, o lúdico proporciona o desprendimento de certas situações, por vezes pesarosas, construindo interações potencialmente positivas.

Diante disso, esta pesquisa tem o objetivo de analisar as perspectivas de sujeitos de diversas áreas sobre o ensino do lúdico na área da saúde. Foi realizada a aplicação de um questionário com perguntas abertas a oito sujeitos que cursavam graduação ou pós-graduação em diferentes áreas, com o intuito de possibilitar a pluralidade de expressões frente a temática, e os resultados foram tratados com a técnica do Discurso do Sujeito Coletivo (DSC).

\section{Algumas reflexões da literatura sobre o lúdico na área da saúde.}

No estudo de Coscrato, Pina e Mello (2010), os autores realizaram um levantamento bibliográfico com o propósito de analisar na educação em saúde as intervenções lúdicas, isto é, 
as atividades lúdicas como uma ferramenta de mediação para uma aprendizagem prazerosa. 0 estudo foi uma revisão integrativa da literatura e resultou em 16 artigos em temáticas com jogos de computador, dinâmicas, jogos de carta e jogos de tabuleiro (COSCRATO; PINA; MELO, 2010).

Segundo Coscrato, Pina e Mello (2010), as pesquisas resultantes da revisão objetivavam "avaliar a eficácia de intervenções lúdicas como mediadoras na educação em saúde, englobando aspectos como hábitos alimentares, higiene, saúde bucal, crescimento, cuidados com a mãe e o bebê, exposição ao sol, doenças transmissíveis, doenças crônicas e abuso de substâncias" (p. 259). Para os autores há uma necessidade de mais pesquisas do lúdico na educação em saúde delineadas para o ensino superior (COSCRATO; PINA; MELO, 2010).

Em contraste, Fujisawa e Manzini (2006) em seu estudo abordaram as atividades lúdicas no desenvolvimento dos atendimentos em saúde. O estudo com foco em profissionais e acadêmicos de Fisioterapia evidenciou a necessidade das atividades lúdicas na formação acadêmica e ressaltou que a ludicidade se dá por meio da mediação do Fisioterapeuta, diferentemente do estudo de Coscrato, Pina e Mello (2010) em que os autores compreendiam a atividade lúdica como uma ferramenta de mediação.

No estudo de Brito et al. (2009), a pesquisa permeava "a percepção do acadêmico de Enfermagem em relação à realização de práticas lúdicas no cotidiano de fazer em Enfermagem Pediátrica" (BRITO et al., 2009, p. 804). O estudo ressaltou a necessidade de estratégias na formação acadêmica sobre o desenvolvimento dessas práticas para que o manuseio, por exemplo, de um brinquedo não seja efetivamente técnico e sim, com uma contextualidade em que os acadêmicos e profissionais estejam de fato inseridos na situação (BRITO et al., 2009).

O estudo de Angeli, Luvizaro e Galheigo (2012), os autores destacam o relevante papel das vivências lúdicas no ambiente hospitalar, pautado na atuação do Terapeuta Ocupacional. 0 lúdico foi narrado pelos autores como um enfrentamento às condições de fragilidade das vivências de crianças hospitalizadas. No contexto de uma enfermaria, o contar de histórias pelos Terapeutas Ocupacionais construiu condições para uma melhor interação dos envolvidos em um ambiente caracterizado pela tensão (ANGELI; LUVIZARO; GALHEIGO, 2012).

No estudo de Costa et al. (2020), os autores apresentaram um relato de experiência de alunos do curso de Medicina na Universidade Federal do Delta do Parnaíba (UFDPar), em que os alunos se dividiram em grupos com a proposta de construção e prática de materiais lúdicos com as temáticas sobre Dengue, Zika e Chikungunya, Teníase e Criptococose. O teatro com fantoches e as parodias musicais foram as estratégias utilizadas à ludicidade no ensino aos demais alunos (COSTA et al., 2020).

Segundo Costa et al. (2020) a vivência descrita proporcionou aos alunos o desenvolvimento individual e coletivo, o senso crítico, a criatividade, a comunicação e interação entre aluno-aluno e professor-aluno e a ressignificação do conteúdo intelectual para a aplicação prática com abordagem adequada das necessidades reais da sociedade. Ainda sobre o estudo, os autores salientaram a importância da ludicidade no ensino na formação do futuro Médico, tanto em sua formação acadêmica quanto no cuidado em saúde futuramente com seus pacientes (COSTA et al., 2020). 
A literatura evidência diversas práticas da inserção do lúdico na área da saúde, sejam essas da área da Terapia Ocupacional, Fisioterapia, Enfermagem, Medicina, entre outras. As vivências existem do mesmo modo que a explanação do fomento na formação do profissional de saúde para a prática da ludicidade. O lúdico, segundo a literatura, contribui para a construção do acolhimento, na comunicação e na expressão efetiva em analogia com os saberes técnicos específicos de cada área (BRITO et al., 2009; ANGELI; LUVIZARO; GALHEIGO, 2012; COSTA et al., 2020).

\section{Metodologia}

A metodologia utilizada nesta pesquisa é a de abordagem qualitativa (BRASILEIRO, 2013) e para a coleta de dados foi aplicado um questionário com perguntas abertas a oito sujeitos durante os meses de julho a agosto de 2017. Os depoimentos dos sujeitos provenientes do questionário foram tratados com a técnica do Discurso do Sujeito Coletivo (DSC), segundo Lefèvre e Lefèvre (2005).

O Discurso do Sujeito Coletivo é uma técnica desenvolvida pelos pesquisadores brasileiros Lefèvre e Lefèvre (2005) em que expressa o pensamento de um determinado grupo de indivíduos perante um determinado tema. A coleta de dados mais frequentemente realizada se dá por meio da aplicação de questionários com perguntas abertas ou entrevistas de modo individual, para que os indivíduos possam se expressar de maneira fidedigna as suas convicções frente ao tema (LEFÈVRE; LEFÈVRE, 2005; BUENO; BROD; CORRÊA, 2018; BROD; RODRIGUES, 2016).

O DSC consiste, então, numa forma não-matemática nem metalingüistica de representar (e de produzir), de modo rigoroso, o pensamento de uma coletividade, o que se faz mediante uma série de operações sobre os depoimentos, que culmina em discursos-síntese que reúnem respostas de diferentes indivíduos, com conteúdos discursivos de sentido semelhante (LEFÈVRE; LEFÈVRE, 2005, p. 25).

Para produzir os discursos coletivos há quatro operações que precisam ser realizadas, são elas: Expressões-Chave (E-Ch), Ideias Centrais (ICs), Ancoragens (ACs) e o Discurso do Sujeito Coletivo (DSCs). As E-Ch são fragmentos do discurso que se constitui de um entendimento harmônico e viável, no qual possibilite eliminar o restante do discurso sem perder seu significado (LEFÈVRE; LEFÈVRE, 2005; LEFÈVRE; CRESTANA; CORNETTA, 2003).

As ICs são identificadores sintéticos que produzem sentido ao discurso. Pode-se encontrar Ideais Centrais equivalentes em discursos de sujeitos distintos. As ACs são semelhantes às ICs, no entanto, os seus identificadores são sobre a ideologia do discurso e não são obrigatórios. Os DSCs, são o agrupamento dos discursos individuais dos sujeitos, com as ICs e/ou as ACs equivalentes, produzindo assim os discursos do coletivo (LEFÈVRE; LEFÈVRE, 2005; LEFÈVRE; CRESTANA; CORNETTA, 2003).

Na Figura 1 é evidenciado uma breve demonstração da construção do Discurso do Sujeito Coletivo (DSC). 
Figura 1 - Breve demonstração da construção do Discurso do Sujeito Coletivo.

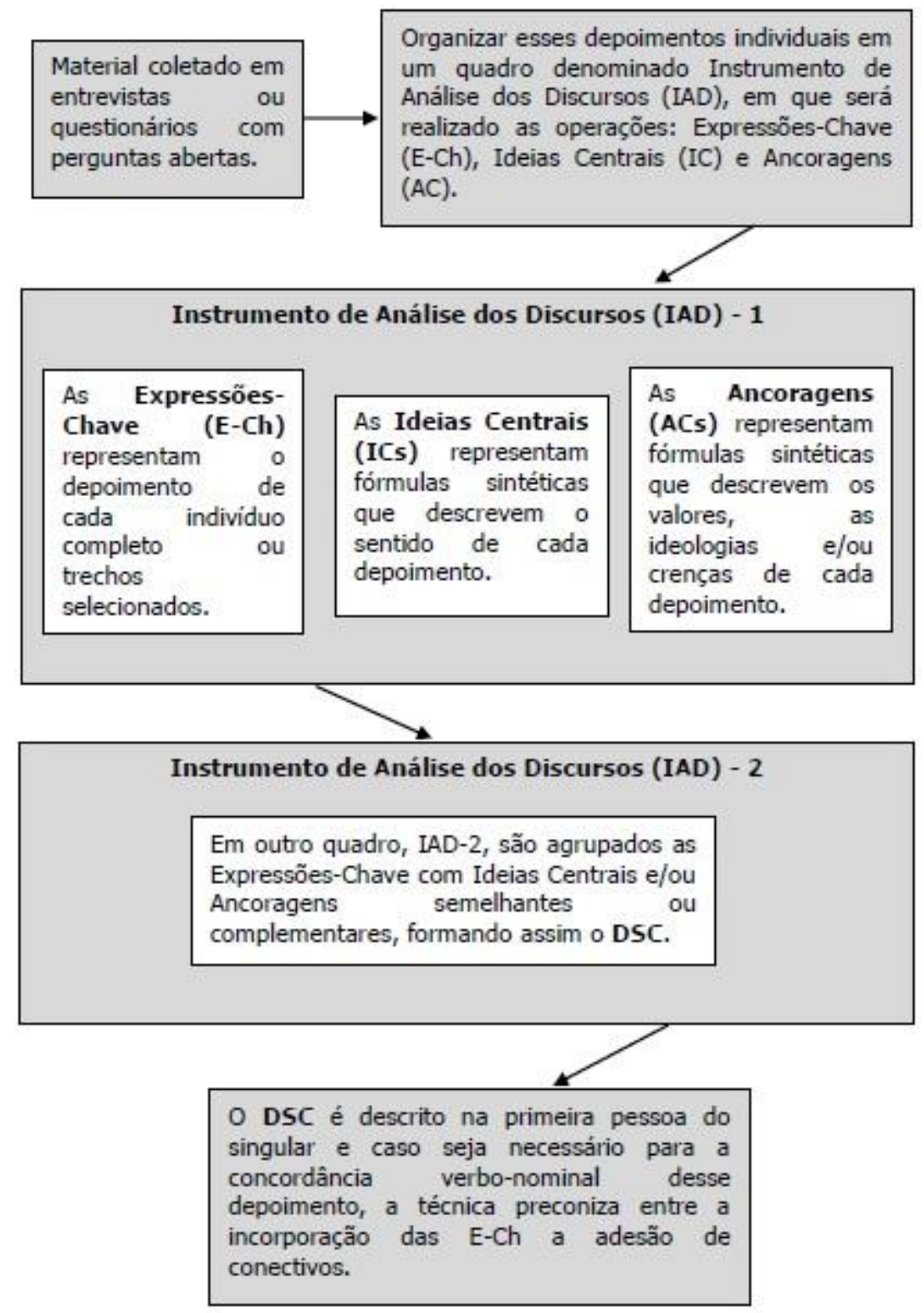

Fonte: Bueno, Bueno e Moreira (2021).

Os sujeitos pesquisados são de áreas diversas, não somente da área da saúde, para que se possa analisar as percepções, de modo global, sobre o tema lúdico e sobre como o ensino dele, auxiliaria ou não, na área da saúde. Os sujeitos foram selecionados de forma aleatória e no período da pesquisa cursavam o ensino superior ou programa de pós-graduação no município de Pelotas, Rio Grande do Sul, Brasil.

Essa seleção deu-se devido a um dos autores desta pesquisa estar se constituindo como pesquisador e assim, tem a intensão de refletir sobre o tema. Os sujeitos que participaram desta pesquisa foram identificados com a vogal A adicionado de um número, para preservação da sua identidade. 
Os dados dos sujeitos pesquisados em relação ao sexo, idade, escolaridade, Instituição, curso e, caso ainda cursando a graduação, o semestre, foi solicitado e são demonstrados na Tabela 1.

Tabela 1 - Demonstração dos dados dos sujeitos pesquisados.

\begin{tabular}{|c|c|c|c|c|c|c|}
\hline \\
\hline Identificação & Sexo & Idade & Escolaridade & Instituição & Curso & Semestre \\
\hline A1 & $\mathrm{M}$ & 27 & $\begin{array}{c}\text { Superior } \\
\text { incompleto. }\end{array}$ & $\begin{array}{l}\text { Fac. Anhanguera } \\
\text { Rio Grande }\end{array}$ & Fisioterapia & 10 \\
\hline $\mathrm{A} 2$ & $\mathrm{~F}$ & 27 & $\begin{array}{c}\text { Superior } \\
\text { incompleto. }\end{array}$ & $\begin{array}{c}\text { Fac. Anhanguera } \\
\text { Pelotas }\end{array}$ & Fisioterapia & 70 \\
\hline A3 & $F$ & 50 & $\begin{array}{c}\text { Pós - } \\
\text { graduação }\end{array}$ & $\begin{array}{c}\text { Universidade } \\
\text { Federal de Pelotas }\end{array}$ & Direito & - \\
\hline A4 & $F$ & 23 & $\begin{array}{c}\text { Superior } \\
\text { incompleto. }\end{array}$ & $\begin{array}{c}\text { Universidade } \\
\text { Federal de Pelotas }\end{array}$ & $\begin{array}{l}\text { Ciências } \\
\text { Biológicas }\end{array}$ & 50 \\
\hline A5 & $\mathrm{F}$ & 26 & $\begin{array}{l}\text { Superior } \\
\text { Completo }\end{array}$ & $\begin{array}{l}\text { Universidade } \\
\text { Católica de } \\
\text { Pelotas }\end{array}$ & $\begin{array}{c}\text { Bacharel } \\
\text { em Ecologia }\end{array}$ & - \\
\hline A6 & $F$ & 50 & $\begin{array}{l}\text { Superior } \\
\text { Completo }\end{array}$ & $\begin{array}{c}\text { Universidade } \\
\text { Federal de Pelotas }\end{array}$ & História & - \\
\hline A7 & $\mathrm{F}$ & 39 & $\begin{array}{c}\text { Pós - } \\
\text { graduação }\end{array}$ & $\begin{array}{l}\text { Universidade } \\
\text { Católica de } \\
\text { Pelotas }\end{array}$ & $\begin{array}{c}\text { Lic. em } \\
\text { Matemática }\end{array}$ & - \\
\hline A8 & $F$ & 23 & $\begin{array}{c}\text { Superior } \\
\text { incompleto. }\end{array}$ & $\begin{array}{c}\text { Fac. Anhanguera } \\
\text { Pelotas }\end{array}$ & Fisioterapia & 6o \\
\hline
\end{tabular}

Fonte: Pesquisa (2017).

O questionário foi composto por duas perguntas abertas, como preconiza a técnica do Discurso do Sujeito Coletivo, sendo essas descritas em: 'Sobre o lúdico: Qual a tua percepção sobre o tema?' e 'Você poderia me explicar de que maneira o lúdico auxiliaria, ou não, no ensino na área da saúde?'. A primeira questão obtinha o intuito de investigar a compreensão dos sujeitos frente ao lúdico, uma vez que, antes de analisar sobre a opinião dos sujeitos em relação ao ensino do lúdico na saúde foi indubitável o entendimento frente ao tema.

Apesar de Lefèvre e Lefèvre $(2005$, p. 40) ressaltarem que se deve evitar perguntas cognitivas, a primeira questão foi intencionalmente formulada com o objetivo de conhecer o entendimento conceitual, ou teórico, dos sujeitos sobre o assunto, caso contrário seria inviável a pesquisa. Os depoimentos da primeira pergunta são descritos no Quadro 1, no Instrumento de Análise dos Discursos - IAD1. 
Quadro 1: Instrumento de Análise dos Discursos (IAD1) da questão 'Sobre o lúdico: Qual a tua percepção sobre o tema?'.

\begin{tabular}{|l|l|l|}
\hline \multicolumn{1}{|c|}{ Expressões-chave } & Ideias Centrais & Ancoragens \\
\hline $\begin{array}{l}\text { (A1) Enxergo como uma maneira alternativa de } \\
\text { aplicar atividades utilizando outros meios, como por } \\
\text { exemplo, um brinquedo. }\end{array}$ & Maneira alternativa & \\
\hline (A2) Pouquíssima. & & \\
\hline $\begin{array}{l}\text { (A3) Penso que é o uso de uma atividade prazerosa } \\
\text { para o desenvolvimento da criatividade de cada } \\
\text { um. }\end{array}$ & $\begin{array}{l}\text { Atividade prazerosa; } \\
\text { Criatividade }\end{array}$ & \\
\hline $\begin{array}{l}\text { (A4) Acredito que seja uma maneira alternativa de } \\
\text { tu ensinar algo a alguém fazendo ela associar com } \\
\text { coisas que sejam do cotidiano dela. }\end{array}$ & Maneira alternativa & \\
\hline $\begin{array}{l}\text { (A5) Vejo como uma forma de ensinar, utilizando } \\
\text { jogos, brincadeiras, oficinas, enfim... fazendo uso } \\
\text { de atividades que não são consideradas o formal } \\
\text { dentro da educação e que auxiliam de maneira } \\
\text { positiva no processo de aprendizagem. }\end{array}$ & Ensino e Aprendizagem; & \\
\hline $\begin{array}{l}\text { (A6) Ser lúdico é proporcionar aprendizagem com } \\
\text { significado, quando estamos realizando um jogo, } \\
\text { uma brincadeira estamos entrando no mundo } \\
\text { infantil, ficamos mais próximo delas onde } \\
\text { conseguimos desenvolver conceitos possíveis delas } \\
\text { compreenderem. }\end{array}$ & Brincadeiras & \\
\hline $\begin{array}{l}\text { (A7) O lúdico é uma maneira diferenciada de } \\
\text { estimular nossos alunos a se interessar pelas aulas, } \\
\text { pois amplia seus conhecimentos de maneira } \\
\text { divertida. O lúdico pelo meu ponto de vista entre } \\
\text { desde um simples desafio, jogo mais complexo, } \\
\text { tecnologias, brincadeiras e outras formas mais. }\end{array}$ & Estimular e aprender de \\
maneira divertida & & \\
\hline $\begin{array}{l}\text { (A8) Os conteúdos lúdicos são muito importantes na } \\
\text { aprendizagem. Isto porque é muito importante } \\
\text { incluir nas crianças a noção que aprender pode ser } \\
\text { divertido. }\end{array}$ & Estimular e aprender de \\
maneira divertida & & \\
\hline
\end{tabular}

Fonte: Pesquisa (2017).

Após a análise dos depoimentos foi realizado o agrupamento conforme suas Ideias Centrais (ICS), as Ancoragens (ACS) não foram perceptíveis para esses depoimentos. 0 Instrumento de Análise dos Discursos - IAD2 da primeira questão é evidenciado no Quadro 2.

Quadro 2: Instrumento de Análise dos Discursos (IAD2) da questão 'Sobre o lúdico: Qual a tua percepção sobre o tema?'.

\begin{tabular}{|c|c|}
\hline Expressões-chave & Ideias Centrais \\
\hline $\begin{array}{l}\text { Acredito que seja uma maneira alternativa de tu ensinar algo a } \\
\text { alguém fazendo ela associar com coisas que sejam do cotidiano } \\
\text { dela. } \\
\text { aplicar atividades utilizando outros meios, como por exemplo, um } \\
\text { brinquedo. }\end{array}$ & Maneira alternativa \\
\hline
\end{tabular}




\begin{tabular}{|l|l|}
\hline Poquissíma & Pouco conhecimento \\
\hline $\begin{array}{l}\text { Penso que é o uso de uma atividade prazerosa para o } \\
\text { desenvolvimento da criatividade de cada um. }\end{array}$ & $\begin{array}{l}\text { Atividades prazerosa; } \\
\text { Criatividade. }\end{array}$ \\
\hline $\begin{array}{l}\text { uma forma de ensinar, utilizando jogos, brincadeiras, oficinas, } \\
\text { enfim... fazendo uso de atividades que não são consideradas o } \\
\text { formal dentro da educação e que auxiliam de maneira positiva no } \\
\text { processo de aprendizagem. }\end{array}$ & \\
$\begin{array}{l}\text { é proporcionar aprendizagem com significado, quando estamos } \\
\text { realizando um jogo, uma brincadeira estamos entrando no } \\
\text { mundo infantil, ficamos mais próximo delas onde conseguimos } \\
\text { desenvolver conceitos possíveis delas compreenderem. }\end{array}$ & Brincadeiras. \\
\hline $\begin{array}{l}\text { O lúdico é uma maneira diferenciada de estimular nossos alunos } \\
\text { a se interessar pelas aulas, pois amplia seus conhecimentos de } \\
\text { maneira divertida, desde um simples desafio, jogo mais } \\
\text { complexo, tecnologias, brincadeiras e outras formas mais. nas } \\
\text { crianças a noção que aprender pode ser divertido. }\end{array}$ & $\begin{array}{l}\text { Estimular e aprender de } \\
\text { maneira divertida. }\end{array}$ \\
\hline
\end{tabular}

Fonte: Pesquisa (2017).

A segunda questão se referia ao entendimento dos sujeitos em relação ao ensino do lúdico na área da saúde, se auxiliaria ou não na opinião dos mesmos. Os resultados dos depoimentos da segunda questão são demonstrados no Quadro 3, no Instrumento de Análise dos Discursos - IAD1.

Quadro 3: Instrumento de Análise dos Discursos (IAD1) da questão 'Você poderia me explicar de que maneira o lúdico auxiliaria, ou não, no ensino na área da saúde?'.

\begin{tabular}{|l|l|l|}
\hline \multicolumn{1}{|c|}{ Expressões-chave } & \multicolumn{1}{|c|}{ Ideias Centrais } & Ancoragens \\
\hline $\begin{array}{l}\text { (A1) É fundamental, pois as vezes é o único meio que } \\
\text { desperta interesse no(s) individuo(s) em determinadas } \\
\text { situações especiais. }\end{array}$ & $\begin{array}{l}\text { Meio de despertar } \\
\text { interesse }\end{array}$ & \\
\hline $\begin{array}{l}\text { (A2) Auxiliaria em um contato facilitado acredito, em } \\
\text { alcançar objetivos terapêuticos. }\end{array}$ & $\begin{array}{l}\text { Auxilia no contato } \\
\text { facilitado }\end{array}$ & \\
\hline $\begin{array}{l}\text { (A3) Não sou da área da saúde, mas posso responder } \\
\text { como paciente eventual. Penso que o lúdico auxilia na } \\
\text { aprendizagem dos que vão lidar com as questões de } \\
\text { saúde, pois o aprender brincando, através de atividades } \\
\text { criativas, é muito interessante na obtenção do } \\
\text { conhecimento, pois facilita a interação entre as pessoas, } \\
\text { sua autoestima, seu autoconhecimento. Acredito que o } \\
\text { lúdico estimula a criatividade desses profissionais para } \\
\text { depois trabalharem diretamente om os pacientes. }\end{array}$ & $\begin{array}{l}\text { Auxilia } \\
\text { aprendizagem. }\end{array}$ & na \\
\hline $\begin{array}{l}\text { (A4) Acredito que por meio de maquetes ou até mesmo } \\
\text { modelos didáticos do assunto a ser abordado. }\end{array}$ & Atividades lúdicas. & \\
\hline $\begin{array}{l}\text { (A5) Eu acredito que o lúdico de maneira geral auxilia } \\
\text { positivamente no ensino, porém não tenho uma visão } \\
\text { focada na área da saúde de maneira tão ampla. }\end{array}$ & $\begin{array}{l}\text { Auxilia } \\
\text { positivamente no } \\
\text { ensino }\end{array}$ & \\
\hline $\begin{array}{l}\text { (A6) Acredito que seja possível desenvolver atividades } \\
\text { lúdicas na área da saúde, da mesma maneira que em sala } \\
\text { de aula. Penso que um simples jogo de passar a bola }\end{array}$ & Atividades lúdicas & \\
\hline
\end{tabular}




\begin{tabular}{l|l|l|}
\hline $\begin{array}{l}\text { possa estar auxiliando um paciente a movimentar os } \\
\text { braços, fazer movimentos laterais, etc. }\end{array}$ & \\
\hline $\begin{array}{l}\text { (A7) O lúdico não tenho dúvida que auxilia também na } \\
\text { área da saúde não só da saúde mais em todas as áreas, } \\
\text { pois na área da saúde na sala de aula podem obter aulas } \\
\text { práticas com vivencias do dia a dia e entre tantos }\end{array}$ & $\begin{array}{l}\text { Aulas práticas com } \\
\text { vivências do dia a } \\
\text { dia; Professores } \\
\text { outros desafios. }\end{array}$ & \\
$\begin{array}{l}\text { Poderia citar aqui diferentes formas de trabalhar o ompromes; } \\
\text { lúdico na saúde, mas o que precisa é professores } \\
\text { comprometidos e ter um pouco mais de tempo para } \\
\text { planejar aulas diferenciadas. Professores que não tem } \\
\text { diferenciadas. }\end{array}$ & \\
medo do novo do desafio. & \\
\hline $\begin{array}{l}\text { (A8) As iniciativas lúdicas potenciam a criatividade, e } \\
\text { contribuem para o desenvolvimento intelectual. }\end{array}$ & $\begin{array}{l}\text { Criatividades; } \\
\text { Desenvolvimento } \\
\text { intelectual. }\end{array}$ & \\
\hline
\end{tabular}

Fonte: Pesquisa (2017).

Após analisar os depoimentos dos sujeitos, os mesmos são agrupados por Ideias Centrais e/ou Ancoragens semelhantes ou complementares, como foi demonstrado na Figura 1. E assim, como foi realizado com a primeira questão, nessa segunda também foi realizado o Instrumento de Análise dos Discursos - IAD2, demonstrado no Quadro 4.

Quadro 4: Instrumento de Análise dos Discursos (IAD2) da questão 'Você poderia me explicar de que maneira o lúdico auxiliaria, ou não, no ensino na área da saúde?'.

\begin{tabular}{|c|c|}
\hline Expressões-chave & Ideias Centrais \\
\hline $\begin{array}{l}\text { É fundamental, pois as vezes é o único meio que desperta interesse } \\
\text { no(s) individuo(s) em determinadas situações especiais. }\end{array}$ & $\begin{array}{l}\text { Meio de despertar } \\
\text { interesse }\end{array}$ \\
\hline $\begin{array}{l}\text { Auxiliaria em um contato facilitado } \\
\text { auxilia positivamente no ensino }\end{array}$ & $\begin{array}{l}\text { Auxilia no contato } \\
\text { facilitado. }\end{array}$ \\
\hline $\begin{array}{l}\text { Penso que o lúdico auxilia na aprendizagem dos que vão lidar com } \\
\text { as questões de saúde, pois facilita a interação entre as pessoas, sua } \\
\text { autoestima, seu autoconhecimento. Acredito que o lúdico estimula } \\
\text { a criatividade desses profissionais para depois trabalharem } \\
\text { diretamente com os pacientes. } \\
\text { As iniciativas lúdicas potenciam a criatividade, e contribuem para o } \\
\text { desenvolvimento intelectual. }\end{array}$ & $\begin{array}{l}\text { Criatividade; Auxilia na } \\
\text { aprendizagem. }\end{array}$ \\
\hline $\begin{array}{l}\text { Penso que um simples jogo de passar a bola possa estar auxiliando } \\
\text { um paciente a movimentar os braços, fazer movimentos laterais, } \\
\text { etc. } \\
\text { Acredito que por meio de maquetes ou até mesmo modelos } \\
\text { didáticos do assunto a ser abordado. }\end{array}$ & Atividades lúdicas \\
\hline $\begin{array}{l}\text { na área da saúde na sala de aula podem obter aulas práticas com } \\
\text { vivências do dia a dia e entre tantos outros desafios. } \\
\text { Poderia citar aqui diferentes formas de trabalhar o lúdico na saúde, } \\
\text { mas o que precisa é professores comprometidos e ter um pouco } \\
\text { mais de tempo para planejar aulas diferenciadas. Professores que } \\
\text { não tem medo do novo e do desafio. }\end{array}$ & $\begin{array}{l}\text { Aulas práticas com } \\
\text { vivências do dia a dia; } \\
\text { Professores } \\
\text { comprometidos; } \\
\text { Aulas diferenciadas. }\end{array}$ \\
\hline
\end{tabular}

Fonte: Pesquisa (2017). 
Posteriormente ao agrupamento foram originados os Discursos dos Sujeitos Coletivos (DSCs), apresentados na Discussão dos dados.

\section{Discussão dos dados}

A realização do Instrumento de Análise dos Discursos - IAD1 e Instrumento de Análise dos Discursos - IAD2 resultou em três Discursos do Sujeito Coletivo (DSCs). Para a primeira questão 'Sobre o lúdico: Qual a tua percepção sobre o tema?' foram originados dois discursos denominados de 'Atividade prazerosa para o desenvolvimento da criatividade' demonstrado no Quadro 5 e 'O Lúdico auxilia de maneira positiva no processo de aprendizagem' demonstrado no Quadro 6.

Quadro 5: DSC1- Atividade prazerosa para o desenvolvimento da criatividade.

\section{Atividade prazerosa para o desenvolvimento da criatividade}

Pouquíssima. Acredito que seja uma maneira alternativa de tu ensinar algo a alguém fazendo ela associar com coisas que sejam do cotidiano dela, como também aplicar atividades utilizando outros meios, como por exemplo, um brinquedo, enfim, o uso de uma atividade prazerosa para o desenvolvimento da criatividade de cada um.

Fonte: Pesquisa (2017).

No discurso DSC1, demonstrado no Quadro 5, foi evidenciado que apesar do pouco conhecimento sobre o tema há uma tentativa de associação do lúdico com um brinquedo, com a criatividade, posicionamentos que remetem a temática. $O$ tema lúdico é complexo e por vezes complicado de conceituar na prática, Bataglion e Marinho (2019) em sua pesquisa ressaltaram a dificuldade dos profissionais da saúde na identificação das atividades lúdicas em seus atendimentos, contudo, esses profissionais apresentavam apropriação da ludicidade em suas atividades atrelados aos objetivos específicos dos pacientes.

Talvez o lúdico não seja e nem deva ser conceituado como algo precisamente explícito, mas proporcionado de maneira efetiva e afetuosa em sua dinâmica. Principalmente quando a abordagem está inserida no âmbito da saúde, em que há a complexidade dos contextos sociais, das perspectivas frente a saúde e a doença, estigmas, imaginário e diversas formas de manifestações de sentimentos (BATAGLION; MARINHO, 2019).

No discurso do DSC2, demonstrado no Quadro 6, esse sujeito coletivo relata a percepção do lúdico como uma maneira divertida no ensino e na aprendizagem, além disso, colocou o lúdico como uma maneira não formal na educação. $O$ depoimento expõe a maneira diferenciada na estimulação do aluno e no brincar, isto é, não é somente uma distração dos indivíduos envolvidos, há naquela atividade propósitos a serem desempenhados. 
Quadro 6: DSC2 - O Lúdico auxilia de maneira positiva no processo de aprendizagem.

\section{O Lúdico auxilia de maneira positiva no processo de aprendizagem}

O lúdico é uma maneira diferenciada de estimular nossos alunos a se interessar pelas aulas, pois amplia seus conhecimentos de maneira divertida, desde um simples desafio, jogo mais complexo, tecnologias, brincadeiras e outras formas mais. Nas crianças a noção que aprender pode ser divertido fazendo uso de atividades que não são consideradas o formal dentro da educação e auxiliam de maneira positiva no processo de aprendizagem, é proporcionar aprendizagem com significado, quando estamos realizando um jogo, uma brincadeira estamos entrando no mundo infantil, ficamos mais próximo delas onde conseguimos desenvolver conceitos possíveis delas compreenderem.

Fonte: Pesquisa (2017).

Para Caricchio (2017) o lúdico se constitui como necessário no desenvolvimento teóricoprático. No estudo, a autora realizou uma revisão integrativa de literatura para demonstrar como a Fisioterapia Pediátrica no Brasil tem utilizado o recurso lúdico como um instrumento eficaz ao tratamento de crianças e evidenciou a necessidade na formação do Fisioterapeuta (CARICCHIO, 2017).

A imersão no lúdico, por vezes considerada pelos indivíduos uma perspectiva não-formal na educação, possibilita a articulação entre teoria e prática e na área da saúde permite a aquisição de habilidades, ao mesmo tempo a interseç̧ão de conceitos clínicos e afetivos. As vivências e o entendimento de verdadeiramente estar inserido nessas vivências se constituem como significativas em contextos individuais e sociais (BARBOSA; ZANETTI; SOUZA, 2021; AGUIAR et al., 2020).

No estudo de Bueno, Brod e Corrêa (2018), os autores problematizaram "Como profissionais e acadêmicos de fisioterapia percebem o lúdico em suas práticas junto aos alunos com necessidades educacionais especiais e se é praticado ou não o mesmo por esses sujeitos nos atendimentos, na modalidade de hidroterapia." (p. 1105). Foram seis sujeitos pesquisados e segundo o estudo, o lúdico foi evidenciado como uma ferramenta que proporcionava motivação no tratamento ao paciente (BUENO; BROD; CORRÊA, 2018).

Além disso, por meio do lúdico o Fisioterapeuta mantinha uma relação com o paciente de confiança e afetuosidade, proporcionando efetividade e humanização nos atendimentos (BUENO; BROD; CORRÊA, 2018). Nesse sentido, ressalta-se o pensamento de Maturana (2004) com a importância dessas interações, bem como a inserção de fato, na ação. Isto é, estar imerso dentro do contexto, de modo racional e emocional, por exemplo, estar presente de fato, em uma brincadeira com o paciente.

O segundo questionamento descrito em 'Você poderia me explicar de que maneira o lúdico auxiliaria, ou não, no ensino na área da saúde?' resultou em um Discurso do Sujeito Coletivo (DSC), com o título 'O Lúdico na saúde facilita a interação, a criatividade e o desenvolvimento.' demonstrado no Quadro 7. 
Quadro 7: DSC3 - O Lúdico na saúde facilita a interação, a criatividade e o desenvolvimento.

\section{O Lúdico na saúde facilita a interação, a criatividade e o desenvolvimento.}

Penso que o lúdico auxilia na aprendizagem dos que vão lidar com as questões de saúde, pois facilita a interação entre as pessoas, sua autoestima, seu autoconhecimento, as iniciativas lúdicas potenciam a criatividade, e contribuem para o desenvolvimento intelectual. Um simples jogo de passar a bola possa estar auxiliando um paciente a movimentar os braços, fazer movimentos laterais, etc., bem como por meio de maquetes ou até mesmo modelos didáticos do assunto a ser abordado, possivelmente, é o único meio que desperta interesse no(s) individuo(s) em determinadas situações especiais. Poderia citar aqui diferentes formas de trabalhar o lúdico na saúde, mas o que precisa é professores comprometidos e ter um pouco mais de tempo para planejar aulas diferenciadas. Professores que não tem medo do novo e do desafio, provavelmente auxiliaria em um contato facilitado, como positivamente no ensino.

Fonte: Pesquisa (2017).

No discurso DSC3, demonstrado no Quadro 7, o lúdico no ensino da área da saúde foi descrito por esse sujeito coletivo como uma prática inegavelmente significativa. O discurso DSC3 não somente expõe um exemplo simples da experiência, como também fomenta o estímulo as ações com o tema para que as trocas de saberes se desenvolvam cada vez mais com intencionalidade.

Um simples jogo de passar a bola possa estar auxiliando um paciente a movimentar os braços, fazer movimentos laterais, etc. (DSC3).

A complexidade na construção de atividades lúdicas e também, por vezes, os melindres que as envolvem são desafios ainda constituídos dentro e fora do meio acadêmico. Contudo, após as experiências vividas há o entrelaçamento de emoções, o autoconhecimento, a aproximação entre os indivíduos, o desenvolvimento e as ressignificações dos assuntos abordados (PEREIRA et al., 2021; SANTOS et al., 2020).

Inegavelmente, o lúdico precisa ser compreendido como algo indissociável do ensino e da aprendizagem, ele permite aos mesmos, significados racionais e emocionais, como anteriormente já descrito por Maturana (2004). Por meio do brincar em suas diversas variáveis pode-se expressar sentimentos e é também, a partir dele que as percepções do desenvolvimento são adquiridas.

Da mesma forma, existe a provocação perante o desempenho do lúdico em qualquer faixa etária, não apenas o relacionando a atividades com crianças. Dos discursos emergem a importância das vivências em que a ludicidade rememora, aproxima, estimula, comunica, e dentro da área da saúde, também cuida. Igualmente, os discursos demonstram a complexa interdisciplinaridade e a pluralidade das atividades lúdicas como proposta de interação.

\section{Considerações Finais}

A partir dos resultados obtidos nesta pesquisa foi observado que os sujeitos pesquisados obtinham entendimento sobre o tema, apesar da complexidade de conceitualização e os autores desta pesquisa compreendem também que a temática se faz profunda. Ainda assim, os 
discursos vincularam o lúdico como uma ferramenta que proporciona a aproximação efetiva dos objetivos, isto é, uma ferramenta que coopera no desenvolvimento múltiplo dos envolvidos.

Os depoimentos ressaltaram a relevância da abordagem do lúdico no ensino na área da saúde, em que as atividades promovem estímulos, são criativas, prazerosas e afetivas. Contudo, a prática dessas atividades necessitam de intencionalidade para que não ocorra a insignificância ou a escassez de melhorias dessas interatividades.

Sob o mesmo ponto de vista, que a disponibilidade e o comprometimento são indubitáveis ao proporcionar atividades que envolvam o lúdico. Nesse sentido, expõe-se que é imprescindível refletir sobre essas dinâmicas, sejam essas dentro e fora do meio acadêmico, e em promover estudos em relação ao ensino do lúdico nas diversas áreas e em suas diferentes práticas.

\section{Referências}

AGUIAR, A.C.S. et al. A importância dos projetos sociais na formação profissional em fisioterapia. Revista Inova Saúde, Criciúma, v. 10, n. 2, p. 78-86, 2020.

ANGELI, A. A. C.; LUVIZARO, N.A.; GALHEIGO, S.M. O cotidiano, o lúdico e as redes relacionais: a artesania do cuidar em terapia ocupacional no hospital. Interface-Comunicação, Saúde, Educação, Botucatu, v. 16, n. 40, p. 261-272, 2012.

BARBOSA, N.G.; ZANETTI, A.C.G.; SOUZA, J. Genograma e ecomapa como estratégias lúdicas de ensino de enfermagem na atenção primária à saúde. Revista Brasileira de Enfermagem - REBEn, Brasília, v. 74, n. 3, e20201106, 2021.

BATAGLION, G.A.; MARINHO, A. O lúdico em contexto de saúde: inter-relações com as práticas humanizadas. Motrivivência, Florianópolis, v. 31, n. 57, p. 01-19, 2019.

BOLORINO, N. et al. Percepção dos alunos da disciplina ludicoterapia sobre o cuidado lúdico: uma pesquisa-ação. Research, Society and Development, Vargem Grande Paulista, v. 9, n. 12, e28191211038, 2020.

BUENO, M.B.T.; BUENO, M.M.; MOREIRA, M.I.G. O uso de tecnologias digitais e mídias sociais por profissionais da saúde no período da pandemia da COVID-19. Revista Thema, Pelotas, v. 20, Edição Especial Covid-19, p. 181-200, 2021.

BUENO, M.B.T.; BROD, F.A.T.; CORRÊA, T.B. Hidroterapia e o lúdico: reflexões de acadêmicos e profissionais de fisioterapia no DSC. Revista Thema, Pelotas, v. 15, n. 3, p. 1104-1114, 2018.

BRASILEIRO, A.M.M. Manual de produção de textos acadêmicos e científicos. São Paulo: Atlas, 2013.

BRITO, T.R.P. et al. As práticas lúdicas no cotidiano do cuidar em enfermagem pediátrica. Escola Anna Nery Revista de Enfermagem, Rio de Janeiro, v. 13, n. 4, p. 802-808, 2009.

BROD, F.A.T.; RODRIGUES, S.C. O conversar como estratégia de formação contínua na tutoria da educação profissional a distância. Revista Brasileira de Educação, Rio de Janeiro, v. 21, n. 66, p. 631-652, 2016. 
CARICCHIO, M.B.M. Tratar brincando: o lúdico como recurso da fisioterapia pediátrica no Brasil. Revista Eletrônica Atualiza Saúde, Salvador, v. 6, n. 6, p. 43-57, 2017.

CINTRA, R.C.G.G.; PROENÇA, M.A.M.; JESUINO, M.S. A historidade do lúdico na abordagem histórico-cultural de Vigotski. Revista Rascunhos Culturais, Coxim, v. 1, n. 2, p. 225-238, 2010.

COSCRATO, G.; PINA, J.C.; MELLO, D.F. Utilização de atividades lúdicas na educação em saúde: uma revisão integrativa da literatura. Acta Paulista de Enfermagem, São Paulo, v. 23, n. 2, p. 257-263, 2010.

COSTA, T.R.M. et al. Aplicação do lúdico para o ensino de saúde na educação médica da cidade de Parnaíba, Piauí: relato de experiência. Revista Eletrônica Acervo Saúde / Electronic Journal Collection Health, v. 12, n. 11, p. 1-8, 2020.

FUJISAWA, D.S.; MANZINI, E.J. Formação acadêmica do fisioterapeuta: a utilização das atividades lúdicas nos atendimentos de crianças. Revista Brasileira de Educação Especial, Bauru, v. 12, n. 1, p. 65-84, 2006.

LEFÈVRE, A.M.C.; CRESTANA, M.F.; CORNETTA, V.K. A utilização da metodologia do discurso do sujeito coletivo na avaliação qualitativa dos cursos de especialização "Capacitação e Desenvolvimento de Recursos Humanos em Saúde-CADRHU", São Paulo - 2002. Saúde e Sociedade, São Paulo, v. 12, n. 2, p. 68-75, 2003.

LEFÈVRE, F.; LEFÈVRE, A.M.C. Discurso do sujeito coletivo: um novo enfoque em pesquisa qualitativa (desdobramentos). 2. ed. Caxias do Sul: Educs, 2005.

MASSA, M.S. Ludicidade: da etimologia da palavra à complexidade do conceito. APRENDER Caderno de Filosofia e Psicologia da Educação, Vitória da Conquista, v. 9, n. 15, p. 111-130, 2015.

MATURANA, H.R. Amar e brincar: fundamentos esquecidos do humano do patriarcado à democracia. São Paulo: Palas Athena, 2004.

MIRANDA, C.G.L.; SOARES-SOBRINHO, J.L.; CASTRO, M.S. Validação de vídeo lúdico: educação em saúde de idosos hipertensos para a promoção do uso correto e seguro de medicamentos e conhecimento sobre sua doença. Revista Observatório, Palmas, v. 5, n. 6, p. 821-833, 2019.

PEREIRA, B.S et al. Atividade lúdica e inovadora para o ensino das principais pulgas e doenças transmitidas por elas de importância médica. Revista Gestão, Inovação e Tecnologias GEINTEC, Aracaju, v. 11, n. 1, p. 5865-5879, 2021.

RIBEIRO, S.C.D.; BONINI, L.M.M.; MELO, T.R.C. O lúdico e o ensino universitário combinam?. Pesquisa em Foco, São Luís, v. 25, n. 2, p. 21-37, 2020.

SANTOS, K.R. et al. Jogo lúdico e educativo como ferramenta de ensino e aprendizagem em parasitologia. Revista Brasileira de Educação e Saúde, Pombal, v. 10, n. 1, p. 70-79, 2020. 